\title{
Science Teacher Preparation: Themes of Exemplary STEM Inquiry Instruction
}

\author{
Liping Wei ${ }^{1}$, Teresa LeSage-Clements ${ }^{2}$ \\ ${ }^{1}$ Assistant Professor in Curriculum and Instruction, University West, Suite 228, 3007 North Ben Wilson Street, Victoria, \\ Texas, 77901, USA \\ ${ }^{2}$ Associate Professor in Science Education, School of Education, Health Professions, and Human Development, \\ University of Houston-Victoria, TX, USA
}

Correspondence: Liping Wei, Assistant Professor in Curriculum and Instruction, University West, Suite 228, 3007 North Ben Wilson Street, Victoria, Texas, 77901, USA.

\author{
Received: January 21, 2019 Accepted: March 4, $2019 \quad$ Online Published: March 13, 2019 \\ doi:10.11114/ijce.v2i1.4145 \\ URL: https://doi.org/10.11114/ijce.v2i1.4145
}

\begin{abstract}
In response to increased attention to STEM teacher preparation, this paper intends to investigate the inquiry methods for improving STEM teaching and learning through unpacking the instructional implementation of a "Science as Inquiry" course in the teacher education program of a public university in a Southwestern state of the U.S. The purpose is examining the features underlying inquiry approach to science instruction, and therefore facilitating the dissemination and adoption of effective STEM instructional practices. Five themes are illuminated, presenting an exemplar of inquiry-based science instruction: a) nourishing an inquiring mind; (b) seeking the depth of understanding; (c) enacting guided inquiry; (d) cultivating cooperative learning; and (e) emphasizing experience-based learning. It is hopeful that this study can highlight the continued need for innovations in STEM teaching pedagogies and contribute to nation's commitment to supporting and improving STEM education.
\end{abstract}

Keywords: science as inquiry, teacher education, inquiry approach to science instruction

\section{Introduction}

The shortage of high-quality STEM (Science, Technology, Engineering, and Mathematics) teachers is one of the most pressing challenges facing the United States. The current demand of STEM teachers across the nation greatly outweighs the supply of qualified teacher candidates, and it is up to our generation of teacher educators to close this gap as we strive for global competitive advantage through the development of STEM research and education.

Some students are left behind academically, especially in STEM education and may never catch up because year after year they attend low-performing schools and have inexperienced teachers and/or teachers out of their content expertise. In addition, student achievement is lower in many schools with a majority of socio-economically disadvantaged students. These schools have lower teacher retention and greater teacher attrition than suburban schools. The students suffer the most unequal education, lower standardized test scores, poor preparation for college rigor, and the lack of opportunity to learn skills for careers with more earning potential. Teacher shortages and hiring underprepared teachers in these schools are contributing to the problems (Carroll \& Foster, 2010; Leal, 2017). These students are doomed to instructional losses that cannot be regained (Sanders \& Rivers, 1996). Billions of tax dollars are invested each year in teacher preparation programs, professional development training, new teacher recruitment, and loss time because of teachers leaving the profession (LeSage-Clements et al., 2013; Ingersoll, 2002; Ingersoll \& Merrill, 2012). The reasons teachers leave the profession are beyond the scope of this paper, but well prepared teachers in their content discipline, pedagogy, and leadership support have greater efficacy (Darling-Hammond, 2003; Guarino, Santibanez, \& Daley, 2006). Teachers need support, resources, and better training, especially in the STEM disciplines.

STEM education is extremely important to the U.S. in its ability to motivate students to create and invent, lead in discoveries, and educate people with the knowledge and skills to obtain jobs and retool for the future. The Next Generation Science Standards (NGSS) (2018) with crosscutting themes connected with engineering emphasizes "science education is central to the lives of all Americans. A high-quality science education means students will 
develop an in-depth understanding of content and develop key skills-communication, collaboration, inquiry, problem solving, and flexibility — serving them throughout their educational and professional lives."

In response to the needs of STEM educators, President Obama articulated a clear priority for STEM teacher education by claiming that "We want to prepare 100,000 new teachers in the fields of science and technology and engineering and math" in his 2011 State of the Union Address (Obama, 2011). Attention has increasingly focused on the shortage of qualified STEM teachers. Under such backdrop, an undergraduate course "Science as Inquiry" was offered during 2015 in the teacher education program at a public university in a southwestern state of the U.S., which aims to prepare qualified teachers for secondary physics and chemistry education.

There is a need to use more qualitative research to study classroom pedagogy and get back to the heart of science, which naturalistically leads to new insights. Naturalistic inquiry is not a verification of predetermined idea or predefined. It is natural and the results must be taken as they are discovered (Sherman \& Webb, 1995). This research investigates the inquiry methods for improving STEM teaching and learning through unpacking the instructional implementation of a "Science as Inquiry" course. The purpose of the study is to facilitate the dissemination and recommendation of effective STEM instructional practices and education experiences that prioritize hands-on learning to increase student engagement and achievement.

\section{Methodology}

Qualitative methods are employed, which is characterized by discovery, exploration, theory/hypothesis generation, and narrative description. Qualitative researchers contend that research is value-bound, should use rich and thick description to reflect "reality" or get close to "reality" (Denzin \& Lincoln, 2005; Lincoln \& Guba, 1985). Following this line of reasoning, data were collected through observation of the classes focusing on how the teacher candidates are taught to utilize inquiry methods as an approach to science instruction. A primary record was built up through videotaping 20 classes of this course and note taking of these observations, thereby getting piles of thick descriptions and field notes. Based on the primary record, a "preliminary reconstructive analysis" (Carspecken, 1996, p. 42) was conducted, including constructing meaning fields, making horizon analysis, making validity claims, distinguishing backgrounding from foregrounding, making power analysis and role analysis, and developing coding scheme. Member checking and peer debriefing were also used to minimize researcher bias and increase credibility of the study. The analysis was inductive, constructive, and an interpretative exploratory process to view the habitat (the science education class) from the eyes of the examinees. The intent was to describe and take into account the context, to emphasize what was observed, to be flexible and develop the themes as outcomes of the research process (Bryman, 2004).

What is worth mentioning is that Liping, the $1^{\text {st }}$ author, is not a researcher with the background of science education. Instead, she was engaged in this study as a qualitative methodologist who conducted observation from the angle of a detached, unobtrusive, and marginal onlooker. Due to her limited knowledge in this particular content area, she restrained herself from acting as a participant-observer who partakes class activities alongside students. Rather, she sat in a position away from the whole class while the instructor and students went about their everyday learning activities, observing what was going on in each of the classes and recording what was observed in a manner as impartial as possible. She attempted to make her notes stay close to the real happenings in the scene through keeping a chronological record of the occurrences in the third person tone, without much self-conscious reflection. Therefore, her records were straightforward and included a large number of actual dialogues and descriptions. In contrast to Liping, Teresa, the 2nd author, is a seasoned science teacher educator who inevitably integrated a lot of personal perceptions and interpretations to the field note. Each researcher brings in her own experience and points of view, and emphasizes different facets of the study. Collectively, they have illuminated the multifaceted characteristics of the "science as inquiry" teaching method comprehensively and thoroughly.

\section{Findings}

Finally, five salient themes were brought to the forefront, demonstrating how this course has unfolded as a wonderful exemplar of inquiry-based science instruction. The five themes are: (a) nourishing an inquiring mind; (b) seeking the depth of understanding; (c) enacting guided inquiry; (d) cultivating cooperative learning; and (e) emphasizing experience-based learning. The following session will illuminate them in detail.

\subsection{Nourishing an Inquiring Mind}

A very prominent characteristic of the course is that it attaches great importance to the nourishment of students' inquiring minds. Whenever students called upon the instructor to assist them, the instructor was quick to use such an opportunity to generate questions back to students, which helped them to get closer to the core of the questions and solutions by themselves. A good example is when a student asked her for a direct answer about a non-working circuit, she replied, "Hmm, what do you think could be the possible explanation behind it?" 
Not only did the instructor raise probing questions, students also openly asked questions and freely discussed among themselves. The class is brimmed with the recurrences of questioning, thinking, discussing, more questioning, more thinking, more discussing, experimenting, and learning. A typical dialogue is recorded as below to reflect the inquiring nature of the class:

Student A: "I have a question. If we do X, will that bulb be brighter?"

Group: "No, no."

Instructor: "But, why not?"

Students attempt to frame reply to instructor's question.

Student B: "Technically, it has twice the brightness, so X should behave Z".

Instructor: "Probably, you can do simulation. Why don’t you use an ammeter and see how it works!"

Another example is that once the instructor showed a picture using a projector, asking students whether the current increases, decreases, or remains the same. In thinking about the answer, students got into a heated discussion concerning what the current is supposed to represent, another question initiated by one student. The instructor listened to the students thinking aloud, questioning, and debating quietly and patiently, completely letting the students take over the exploration. When it came to the point where students' responses seemed to have been exhausted and an intense desire for the right answer loomed, the instructor stepped in. Still, not providing a direct answer or making any evaluative judgment about students' discussion, she said, "I think you should set it up and measure." A couple of students rose right away, picked up materials, and started setting up a circuit to measure the current. Other students followed as well.

It is clearly seen that rather than giving direct answers or confirming or rejecting students' responses rightly, the instructor endeavors to generate questions and answers, informed ideas, and even wild guesses from students. She invariably encourages students to take adventures with experiments to test their various thinking and hypotheses so as to find answers on their own. Moreover, the instructor appears very comfortable with not having "right" or "preferred" answer from students. She also admits to students that she does not know all, which breaks down a traditionally conceived "authoritative" teacher image. Instead, she presents to students the teacher image as a knowledge explorer, questing for truth shoulder to shoulder with students. All these characteristics make this course an ideal arena that welcomes different perspectives, stimulates creativity and an inquiring mind.

\subsection{Seeking the Depth of Understanding}

The instructor made efforts to instill into students the belief that having the right answer is not the most important. What really matters is the depth of understanding. Whenever the instructor reviewed students' homework, she never satisfied herself with getting a direct answer. A valid explanation must be provided from students to be considered acceptable.

When helping students to prepare for the midterm exam, the instructor stressed that what she expected was not a simple answer like "Yes" or "No," "Right" or "Wrong," but an elaboration of the concepts and mechanism substantiating the answer. A simple answer as such would not be given credit. As stated on the course syllabus, "A great deal of emphasis is placed on your ability to provide a written discussion of the concepts you are studying, as well as the reasoning you use to arrive at your conclusions." This belief is also reflected in journal writing that requires students to reflect upon their learning and describe it in their own language.

Another scene that has stood out is when the instructor led students to revisit a knowledge point they had learned before. She first of all drew an electric circuit on the board, for the purpose of clarifying a problem she felt might not have been made clear in the previous class. Students started discussing about it, hypothesized different situations (taking out a bulb from somewhere, adding a line somewhere, etc.), and projected answers. One student surmised, "I have a question. If we do X, will Y happen?" Other students replied, "No, no, not likely." Instead of letting the class get an answer or reach a consensus quickly, the instructor responded, "Why not?" Students were then further inspired and engaged in a deeper level of thinking.

The instructor indicated to students that she wanted to make sure they are confident enough in the knowledge point. She finally concluded the review session by saying, "You also need to do this with your students in your teaching. Sometimes, they say they are sure about something, but when you ask them again, 'Are you sure?' They changed their mind." Through providing an in-depth review of the prior knowledge before proceeding to the next step, the instructor illustrated to students vividly the significance of seeking the depth of understanding.

Probably influenced by this class culture, students are never hesitant to share their confused state of mind. They know that this is not to be viewed as anything shameful, but a good threshold to the expansion of the breadth and depth of knowledge. Where there is confusion and desire for truth, there is the portal of exploration and learning. 


\subsection{Enacting Guided Inquiries}

Students in this course were never presented with the subject matter in its final form. Instead, they were guided by the instructor to engage in inquiry-based discoveries. For example, there was once the class started with two pictures shown by the instructor. One was a circuit with resistance, battery, and switch, and the other was a water pump with valve, pump, and a line. The instructor used analogy as a tool to initiate student thinking and inquiry by asking "what would happen if you think of electrons as water? Can we use water pump analogy for electrical circuit?" Students began debating spiritedly. They were not only prompted to think about similar concepts in a new light, but also propose their own hypotheses. One student asked, "Can we use the analogy of sound waves for electric circuit?" As soon as he said this, seeming to have figured out something, he went, "Oh, but sound waves can travel in vacuum as well." Stimulated by this new analogy, students went into another round of thinking, inquiry, and discovery.

At the end of almost each class, the instructor would let students share what they have learned and how they have learned it. Different groups usually gain different learnings due to different experiences. Students therefore feel inspired to share their learning and discuss possible associations between different discoveries, which powerfully help students define and extend their learning.

For the inquiry-based classroom to be created, the instructor provided students with various meaningful academic activities, such as group-work experiment, engineering design activity, demonstration, etc., and saw to it that students spent an adequate amount of time engaged in these inquiry and received timely instruction and guidance either individualized or in small group. Moreover, in this process, the instructor was always ready to make available all types of resources needed by students in their inquiries.

Key to the guided inquiries is the instructor's questioning, which made students think through dialogue and experimentation until answers, solutions, and knowledge are devised and derived by the students. Some typical questions from the instructor are listed as below:

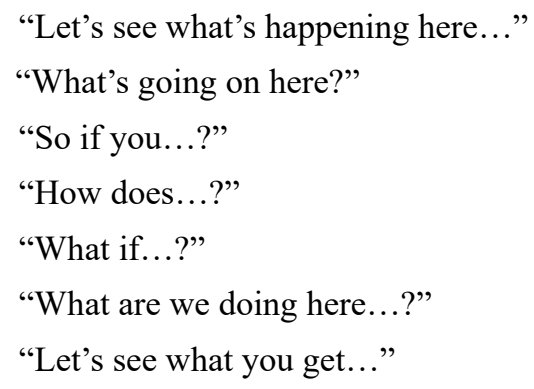

Some of them were not questions ostensibly, but played the role of questions to a certain extent, such as "Let's see what's happening here..." and "Let's see what you get..." Others were framed in the manner that sounded very friendly and spontaneous that easily put off students' anxiety and fear of saying anything wrong and looking stupid, but allowed them to freely conjecture and explore on an equal platform. While posing questions, the instructor successfully let students feel that their answers have value for her and are being expected. For example, when moving to one table during group work, the instructor said, "Tell me what you get when you change your configuration because I am really interested."

Another keen observation pertaining guided inquiries is: While the instructor guided students to reason out loud, play with ideas, realize any misconception, and figure out solutions, students seemed to eventually arrive at the discoveries and knowledge in a very natural, relaxing, and stimulating manner, with little awareness of the process by which they reached it. For instance, after moving to a group whose members were setting up a circuit, the instructor stood patiently for two minutes, trying to understand the problem. Then she asked, "So are we happy?" A student from the group answered, "If we put X here, the brightness should decrease." The instructor nodded and encouraged them to test this conjecture. Without letting the students feel that they were being helped, the instructor became part of the group and made some changes in the circuit. At the time the circuit was created successfully, the instructor withdrew quietly. The students applauded exuberantly as if they made it independently.

Additionally, what is worth mentioning about guided inquiries is that the instructor paid equal attention to fostering students' self-initiated learning throughout the instruction. She effectively built a supportive and positive classroom atmosphere, in which, students' independent and individualized learning were greatly facilitated. Instead of relying on the instructor giving a definite answer or lecturing on the content knowledge, students were actively engaged in thinking, finding answers, and discovering knowledge on their own. They fully took the initiative, and were held responsible for their own learning. 


\subsection{Cultivating Cooperative Learning}

Cooperative learning was manifested very distinctly in observation. In group work, students thought aloud to one another, and shared, negotiated and modified one another's ideas. Working collaboratively towards a common goal, they supported one another's learning, and in this process, everyone's strengths were capitalized on, everyone could learn from each other, everyone contributed to one another's knowledge mastery, and everyone succeeded when the group succeeded. Not only intra-group but also inter-group interactions were frequently observed. For instance, when a group working on a circuit using nichrome wire encountered a trouble, they explained their situation to an adjacent group. Though this group did not seem to have an immediate answer either, they promptly jumped in and started discussing alternatives together.

The classroom culture was cultivated as such that no one laughed at those who did not know yet. Students freely exchanged ideas and problems with each other, because they understood that ultimately they were not only responsible for their own learning, but also others'. Therefore, it was very commonly observed that students explained to one another what they had learned or were learning and assisted one another with understanding and completion of assignments.

This kind of peer tutoring, more often than not, was voluntary rather than arranged by the instructor. Faster students who had just experienced the learning process may be more aware than the instructor of what was giving other students difficulty, so may be better able to explain a concept in the language that their peers can grasp. Students were witnessed to never hesitate to ask their peers for help, no matter in the class or outside of class. This was also encouraged by the instructor. Once, she invited a student who had an ingenious way of understanding a physics phenomenon to explain it to another student who was experiencing difficulty with understanding it. Using a familiar analogy, the former student indeed made this difficult concept comprehensible to the latter student as if effortlessly, and this turned out to be mutually beneficial. Both of their faces radiated joy. The latter student's puzzle got solved, and the former student' understanding got reinforced and self-esteem elevated. The instructor also benefited by having additional time to work with other students in need of help.

\subsection{Emphasizing Experience-based Learning}

In this inquiry-based classroom, it was evidently observed that the instructor gave top priority to students' personal experience of learning. Each student wrote down their reflection and discoveries in their own language in the journal as aforementioned. Individual groups work on the experiments at respective pace, solving problems they experienced, and led to the learning resulting from their experience. In one end-of-class summary, the instructor asked the group who had learned some "big thing" not to share with others, but let other groups find it out by themselves. Because she pointed out that by experiencing and discovering it themselves, students would have deeper understanding and memories of the knowledge. Throughout the course, no one was observed to idle about, waiting for other students to complete the experiment and get the results. Everyone was an important part of the inquiry, learning from his or her experience as well as all others'.

The most illuminating example of experience-based learning is probably the "Engineering Design Activity," in which students in groups designed and built physics models and explained the mechanisms underlying them. Each group had the option of choosing a topic and creating their own model, which gave a great sense of intellectual freedom, motivation, and ownership to students.

This is an excellent activity that enables students to learn knowledge through actually applying, testing, and discovering it. From brainstorming, to designing, trying, troubleshooting, remodeling, adjusting, and rectifying, without personally experiencing every single step of the activity, they could not eventually learn. Every little success in the experience filled them with joy, no matter it was the working of a small circuit or a slight motion on the ammeter or voltmeter.

The unknown, failures, surprises and exultation abounded in their experience. A group originally planning to develop an electromagnetic gun started confidently. Having made a model using paper roll, water and aluminum foil, they fixed their eyes on ammeter, eagerly expecting it to show the movements as designed. Unfortunately, the experiment did not. They went on to try different manipulations, and finally determined that this was not a working model. Not appearing any fear or anxiety of failing an experiment, they began working on a different model, with the same positivity and confidence.

Another group in an attempt to make periscope somehow ended up cutting it into two halves, which allowed them to view a different image and inspired them to wonder about ray diagram with different mirror settings. Following a lot of tests and modifications, they finally managed to draw a new ray diagram, and gave each other an extended high five jubilantly! They did not know another discovery unexpected was awaiting. A random placement of the telescope created by another group at the image point of their periscope gave rise to a view that made everyone fly into rapture. They could not help but make another high five, and a girl acclaimed excitedly, "This is going to be our patent design and it is called Peri-telescope!"

\section{Summary}

This research produced substantial data to illuminate how science is taught as inquiry in a teacher education course. Five themes were unwrapped in this study: nourishing an inquiring mind, seeking the depth of understanding, enacting guided 
inquiry, cultivating cooperative learning \& sharing, and emphasizing experience-based constructivist instruction. A student's remark made to the instructor in the last class can aptly summarize how the inquiry-based learning has affected students learning, "We learned what we experienced. You can't learn what you didn't experience." An interesting connection with the results of this study is to Dimension 1, Practices in the NGSS: "Inquiry can be interpreted in many ways, but in as in all inquiry-based approaches to science teaching, students' need for themselves to engage in the practices and not merely learn about them secondhand without directly experiencing the practices...nor fully appreciate the nature of scientific knowledge itself, without directly experiencing those practices for themselves." The students in the class under study were fully engaged and learned for themselves that they must experience the science practice in order to fully understand it. It is hopeful that this study can highlight the continued need for innovations in STEM teaching pedagogies and contribute to nation's commitment to supporting and improving STEM education.

\section{References}

Bryman, A. (2004). Social research methods. New York: Oxford University.

Carroll, T. G., \& Foster, E. (2010). Who will teach? Experience matters. National Commission on teaching and America's future (NCTAF). Retrieved from http://www.nctaf.org/NCTAFWhoWillTeach.pdf.pdf

Carspecken, P. (1996). Critical ethnography in educational research. New York and London: Routledge.

Darling-Hammond, L. (2003). Keeping good teachers: Why it matters, what leaders can do. Educational Leadership, 60(8), 6-13.

Denzin, N. K., \& Lincoln, Y. S. (Eds.). (2005). The SAGE handbook of qualitative research. Thousand Oaks, CA: Sage.

Guarino, C., Santibanez, L., \& Daley, G. (2006). Teacher recruitment and retention: A review of the recent empirical literature. Review of Education Research, 76(2), 173-208. https://doi.org/10.3102/00346543076002173

Ingersoll, R. (2002). The teacher shortage: A case of wrong diagnosis and wrong prescription. NASSP Bulletin, 86(631), 16-31. https://doi.org/10.1177/019263650208663103

Ingersoll, R., \& Merrill, L. (2012). Seven trends: The transformation of the teaching force. CPRE Report (\#RR-80). Philadelphia: Consortium for Policy Research in Education, University of Pennsylvania.

Leal, F. (2017). Worsening teacher shortage puts more underprepared teachers in classrooms, report says. Retrieved from

https://edsource.org/2017/worsening-teacher-shortage-puts-more-underprepared-teachers-in-classrooms-report-say s/576770

LeSage-Clements, T., Patton, B., Prince, D., \& Carlson, P. (2013). Billions of dollars wasted: New teacher preparation models needed. National Social Science Association. Retrieved from http://www.nssa.us/journals/pdf/NSS_Journal_41_1.pdf p 64

Lincoln, Y. S., \& Guba, E. G. (1985). Naturalistic inquiry. Beverly Hills, CA: Sage.

Next Generation Science Standards (NGSS). (2018). Retrieved from http://www.nextgenscience.org

Obama, B. (2011). President State of the Union Address. Retrieved from https://obamawhitehouse.archives.gov/the-press-office/2011/01/25/remarks-president-state-union-address.

Sanders, W. L., \& Rivers, J. C. (1996). Cumulative and residual effects of teachers on future student academic achievement (Research Progress Report). Knoxville, TN: University of Tennessee Value-Added Research and Assessment Center.

Sherman, R. R., \& Webb, R. B. (Eds.). (1995). Qualitative research in education: Focus and methods. New York, NY: Falmer Press.

Wei, L., \& LeSage-Clements, T. (2017). Science instruction: narrative inquiry's best methods. Paper presented at the National Social Sciences Association.

https://www.nssa.us/journals/pdf/NSSA_Proceedings_2017_Las_Vegas_2.pdf

\section{Copyrights}

Copyright for this article is retained by the author(s), with first publication rights granted to the journal.

This is an open-access article distributed under the terms and conditions of the Creative Commons Attribution license which permits unrestricted use, distribution, and reproduction in any medium, provided the original work is properly cited. 